\title{
Annealing-Free Efficient Vacuum-Deposited Planar Perovskite Solar Cells with Evaporated Fullerenes as Electron-Selective Layers
}

Dewei Zha o, ${ }^{1,2,+* *}$ Weijun Ke, ${ }^{1, \ddagger}$ Cor ey R. Gr ice,${ }^{1}$ Al exander J Cimar ol i,${ }^{1}$ Xinxuan Tan, ${ }^{1}$ Mengjin Yang, ${ }^{2}$ Robert W. Coll ins, ${ }^{1}$ Hongmei Zhang, ${ }^{3}$ Ka Zhu,${ }^{2}$ and Yanfa Yan $^{1, *}$

${ }^{1}$ Department of Physics and Astronomy and Wright Center for Photovoltaics Innovation and Commercialization, The University of Toledo, Toledo, $\mathrm{OH} 43606$, United States

*Address correspondence to: dewei_zhao@ hotmail.com (D.W. Zhao), yanfa.yan@utoledo.edu (Y.F. Yan)

${ }^{2}$ Chemical and Materials Science Center, National Renewable Energy Laboratory, Golden, Colorado 80401, United States

${ }^{3}$ Institute of Advanced Materials and Key Laboratory for Organic Electronics \& Information Displays, Nanjing University of Posts \& Telecommunications, Nanjing 210023, P.R. China

${ }^{\ddagger}$ These authors contributed equally to this work.

KEYWORDS: Perovskit e solar cells, vacuum-deposit ion, el ect r on-sel ect ive layer, hole blocking 1 ayer, $\mathrm{C}_{60}$ and $\mathrm{C}_{70}(\mathrm{ful} 1 \mathrm{erenes})$ 


\section{Abstract}

We present efficient metal oxide-free and annealing-free planar perovskite solar cells with the regular cell structure using vacuumdeposited fullerenes $\mathrm{C}_{60}$ and $\mathrm{C}_{70}$ as the electron-selective layers and vacuum-processed perovskites as the light absorbers. The devices wit h an ultrathin $\mathrm{C}_{60}$ layer $(5.5 \mathrm{~nm})$ yielded a n average power conversion efficiency of $14.3 \%$ and a maximum efficiency of $15.7 \%$. The best-performing cell produced a steady-state efficiency of 14.6\%. The high performance is at tributed to the efficient blocking of holes and extraction of electrons by $\mathrm{C}_{60}$ due to a favorable energy level alignment between the $\mathrm{C}_{60}$ and the fluorine-doped t in oxide electrodes. Wit h the realization of efficient cells, the annealing-free vacuum deposition of perovskite absorbers and $\mathrm{C}_{60}$ or $\mathrm{C}_{70}$ electron-selective 1 ayers and intermediate 1 ayers demonstrates it $\mathrm{s}$ power for fabricat ing all-perovskit e tandem sol ar cells. 


\section{Introduction}

Organic-inorganic lead halide perovskite based solar cells have been extensively investigated over the past few years due to the excellent photovoltaic properties of perovskites such as high optical absorption coefficient, long charge carrier lifetime, high carrier mobil it y, and band gap tenabil it y [1-5]. Mor eover, perovskite solar cells can be made by low cost solution process at low temperature, enabling roll-to-roll manufacturing using flexible substrates. Perovskite-based solar cells have been considered recently as the most promising photovoltaic technology [6, 7], with their power conversion efficiencies (PCEs) rapidly $\mathrm{r}$ ising from $3.8 \% \mathrm{t}$ o a cert if ied $20.1 \%$ [8-15].

The high efficiencies of perovskite solar cells are largely due to the high open circuit voltages $\left(V_{o c} s\right)$, which are attributed to the long carrier 1 if et ime [1,2]. It has been shown that the dominant defects do not create deep energy levels in the band gaps of perovskite absorbers [3, 4], dist inctively different from that seen in the common inorganic solar cell materials. The $V_{\text {oc }}$ deficit, defined by $\mathrm{E}_{\mathrm{g}} / \mathrm{q}-V_{\mathrm{oc}}$, of the record perovskite solar cells, is as small as $0.42 \mathrm{~V}$, approaching that of the best single crystal GaAs thin film solar cell [12]. Therefore, the $V_{\text {oc }}$ of the highefficiency perovskite solar cells has nearly reached it stheoretical value. Unlike $V_{\text {oc }}$, the short-circuit current density $\left(J_{\mathrm{sc}}\right)$ of the high-performing perovskite solar cells still has considerable room for improvement. Typically, high-efficiency perovskite solar cells use a pproximatel y 350-450 
nm thick absorbers, which are not sufficiently thick to fully absorb the incident light. Unfortunately, increasing the thickness of the perovskite absorbers could only lead to lower efficiencies, indicat ing that int rinsic electronic property issues exist for the low temperature processed polycrystalline perovskite thin films. Fabricating tandem cells is a legit imate option for further improving the overall device efficiency and has recently attracted great attention. So far, most perovskite tandem cells reported consist of perovskite solar cells as the top subcells and inorganic solar cells such as $\mathrm{Si}$ and $\mathrm{Cu}(\mathrm{In}, \mathrm{Ga}) \mathrm{Se}_{2}$ cells as the bottom subcells [16-18]. Efficient all-perovskite tandem cells, a preferred a pproach, have not been reported yet. Part of the challenge stems from deposit ing intermediate 1 ayers without damaging the ex ist ing under lying subcells.

The planar cell architecture is preferred for fabricating tandem cells. A typical planar cell consists of a solution-processed or vacuum-processed perovskite absorber layer sandwiched between an electron-selective layer (ESL) and a hole-selective layer (HSL). To avoid any da mage to the exist ing subcel1, the ESL or HSL and the perovskite absorber layer should be deposited preferably by vacuum processes and without additional annealing. Furthermore, compared to solution processes, vacuum processes are expected to result in thin fil ms with better uniformity, smoother surfaces, complete coverage, and more accurately controlled thicknesses. However, to date efficient annealing-free vacuum-processed perovskite solar cells have not been reported. The current high- 
performing perovskite cells generally use either high-temperature processed metal oxide layers such as $\mathrm{TiO}_{2}[19,20]$, solut ion-processed low temper at ure materials such as $\mathrm{ZnO}$ [21], $\mathrm{SnO}_{2}$ [22], and $\mathrm{Cs}_{2} \mathrm{CO}_{3}$ [23], or or ganic materials such as $[6,6]$-phenyl- $\mathrm{C}_{61}$-but yric acid methyl ester $\left(\mathrm{PC}_{60} \mathrm{BM}\right)$ and $\mathrm{C}_{60}$ as the ESL [24]. The high temperature and/or solution processes could potentially either thermally decompose the existing perovskites or dissolve the underlying subcells and therefore would be incapable of producing high-efficiency tandemcells.

Vacuum-processed perovskite-based solar cells have been demonstrated by several groups, and the devices have exhibited promising efficiencies in both regular and inverted architectures [25-31]. The first successful vapor-deposited perovskite solar cells with $15 \%$ efficiency were presented in a regular structure and used high temperature processed compact $\mathrm{TiO}_{2}$ as the ESL [25]. Most high-efficiency vacuum-processed perovskite based solar cells used the inverted structure [26, 27, 31], a mong which the best reported cells with the highest PCE of $16.5 \%$ employed solution-processed poly(3,4-et hylenedioxythiophene):poly(styrene sulfonate) (PEDOT:PSS) and various polymers as the HSLs [28]. Other groups have also reported efficient cells using vacuum-processed perovskite absorbers [26, 27, 30, 31]. Likewise, these cells used either high temperat ure processed compact $\mathrm{TiO}_{2}$ or solut ion-processed HSL/ESLs.

Here, we demonstrate efficient annealing-free vacuum-processed perovskite solar cells using thermal evaporation of both the fullerene 
$\mathrm{C}_{60}$ as the ESL and the perovskite as the 1 ight absorber. We used fullerene $\mathrm{C}_{60}$, because it can function as an ESL [32] and can al so be thermally evaporated $[33,34]$. Ther mally evaporat ed $\mathrm{C}_{60}$ fil ms exhibit good el ectronic properties without post-deposition annealing [35]. The devices with an ultrathin $\mathrm{C}_{60} 1$ ayer $(5.5 \mathrm{~nm})$ showed an average PCE of $14.3 \%$ and a maximum PCE of $15.7 \%$. The best-performing cell produced a steady-state efficiency of $14.6 \%$. Our detailed device characterization revealed that the high performance of our annealing-free vacuum-processed perovskite cells resulted from the use of an ultrathin $\mathrm{C}_{60}$ layer which effectively transfers the electrons and blocks the holes due to the favorable energy level al ignment bet ween $\mathrm{C}_{60}$ and $\mathrm{fl}$ uor ine-doped tin oxide (FTO) electrodes. With the realization of efficient cells, the annealing-free vacuum deposit ion of perovskite absorbers and $\mathrm{C}_{60}$ or $\mathrm{C}_{70}$ electron-selective layers and intermediate layers demonstrates its power for fabricating allperovskit e tandem solar cells.

\section{Experimental section}

\section{Perovskite synthesis}

The deposition of the perovskite films was carried out using a thermal evaporator integrated with a glove box. $\mathrm{CH}_{3} \mathrm{NH}_{3} \mathrm{I}$ and $\mathrm{PbI}_{2}$ were 1 oaded int o their individual crucibles. Two quartz crystal microbalances are placed close to each crucible, monit oring the rate of each evaporation source. In our approach, it is difficult to calibrate and monit or the $\mathrm{CH}_{3} \mathrm{NH}_{3} \mathrm{I}$ rate; therefore, it was preferable to monit or the $\mathrm{CH}_{3} \mathrm{NH}_{3} \mathrm{I}$ vapor phase pressure 
instead. After the crucibles are fil led wit h $\mathrm{CH}_{3} \mathrm{NH}_{3} \mathrm{I}$ and $\mathrm{PbI}_{2}$, the chamber is evacuated to a base pressure of $3 \times 10^{-7}$ Torr. The $\mathrm{PbI}_{2}$ crucible is heated until it s deposition rate reaches our target value. Meanwhile, the $\mathrm{CH}_{3} \mathrm{NH}_{3} \mathrm{I}$ crucible is heated unt il the vacuum pressure is $5 \times 10^{-5}$ Torr. For an optimal deposition condition of the perovskite fil m, the $\mathrm{CH}_{3} \mathrm{NH}_{3} \mathrm{I}$ vapor pressure is kept at $5 \times 10^{-5}$ Tor $r$ by controlling the temperature of $\mathrm{CH}_{3} \mathrm{NH}_{3} \mathrm{I}$ crucible and the deposition rate of $\mathrm{PbI}_{2}$ was kept at $0.75 \AA$ /s, a procedure which achieves the best crystalline perovskite fil ms. The samples for TRPL measurement were coated by poly (methyl met hacrylate) (PMMA).

\section{Device fabrication}

Devices are made on FTO substrates cleaned by sonication in deionized water, acetone, and isopropanol, each for 15 minutes. $\mathrm{C}_{60}$ or $\mathrm{C}_{70} 1$ ayers with variable thicknesses were thermally deposited on the FTO substrates, followed by $\mathrm{CH}_{3} \mathrm{NH}_{3} \mathrm{I}$ vapor-assisted perovskite deposition with the growth conditions of $\mathrm{PbI}_{2}$ rate at $0.75 \AA$ A $/ \mathrm{s}$ and $\mathrm{CH}_{3} \mathrm{NH}_{3} \mathrm{I}$ pressure at $5 \times 10^{-5}$ Torr. After the perovskite deposition, the substrates are removed from the chamber. A solution of electron blocking material was spin-coated on the perovskite fil $\mathrm{m}$ at $6000 \mathrm{r}$ pm for $60 \mathrm{~s}$, which consist s of $68 \mathrm{mM}$ 2,2',7,7'-t et rakis-(N,N-di-pmet hoxyphenyl a mine)-9,9'-spir obifluorene (Spiro-OMeTAD) (Shenzhen Feiming Science and Technology Co., Ltd., 99.0\%), $55 \mathrm{mM} \mathrm{tert-butylpyridine}$ (TBP) (Sigma-Aldrich, 96\%), and $26 \quad \mathrm{mM} \quad$ lithium bis( $\mathrm{t} r$ if 1 u or o met ha nesul fonyl )imide $\quad$ (Li-TFSI) (Sigma-Al drich, $99.95 \%)$ dissolved in a mixed solvent of acetonitrile and chlorobenzene with a 
volume ratio of 1:10. Finally, $40 \mathrm{~nm} A u$ was thermally deposited as top electrode, generating the active area of $0.08 \mathrm{~cm}^{2}$ for all devices.

\section{Film and device characterization}

Perovskite films were imaged with a high resolution field emission scanning electron microscope (SEM) (Hitachi S-4800). Atomic force microscopy (AFM) images were acquired on a Veeco Nanoscope IIIA instrument. The crystal structure of the $\mathrm{CH}_{3} \mathrm{NH}_{3} \mathrm{PbI}_{3}$ fil mon the $\mathrm{C}_{60}$-coat ed FTO was examined by X-r a y diffraction (XRD) (Rigaku Ul t ima III) with $\mathrm{Cu} \mathrm{Ka}$ radiation under operat ing conditions of $40 \mathrm{kV}$ and $44 \mathrm{~mA}$. The absorption spectra of the perovskite $\mathrm{CH}_{3} \mathrm{NH}_{3} \mathrm{PbI}_{3}$ fil $\mathrm{m}$ on $\mathrm{C}_{60}$-coated FTO and the $\mathrm{C}_{60}$ layers with varying thicknesses on FTO substrates were measured by a UVVis spectrophotometer (CARY5000, Varian). All layer thicknesses were determined using a Dektak surface profiler and calibrated by spectroscopic ellipsometry. Current density-voltage $(J-V)$ curves were measured in air under AM1.5G solar ir radiation (PV Measurements Inc.) with a Keithley 2400 Source Meter. EQE spectra were performed on a commercial QE system (PV Measurements Inc.). Transient photoluminescence decays were measured with a time correlated single photon counting system, where the light source is a Fianium Supercontinum high power broadband fiber filter (SC400-2-PP). The excit at ion wavelength was $500 \mathrm{~nm}$ wit h a power of $\sim 25 \mu \mathrm{W}$ on a spot size of $0.02 \mathrm{~mm}^{2}$. The decay curve was fit ted using a double exponential model.

\section{Results and discussion}


Figure 1a depicts the geometry of our perovskite solar cells in the regular cell structure using thermally evaporated compact $\mathrm{C}_{60}$ as the ESL on an FTO coated glass substrate and dual evaporated $\mathrm{CH}_{3} \mathrm{NH}_{3} \mathrm{PbI}_{3}$ perovskit e as the absorber. A 2,2',7,7'-t et r a kis-(N,N-d i-p-met hox y phenyl a mine)-9,9'spirobifluorene (spiro-OMeTAD) as the HSL was spin-coated on the perovskite layer. Finally, the device was finished by the thermal evaporation of Au as the topelectrode. It has been reported that the roles of $\mathrm{C}_{60}$ in inverted planar perovskite solar cells are to facilitate the electron transport as a buffer 1 ayer and smoothen the $\mathrm{PC}_{60} \mathrm{BM}$ surface [24, 36]. In organic solar cells, direct contact between $\mathrm{C}_{60}$ and electrodes is not preferred due to the hole-injection induced quenching of excit ons at $\mathrm{C}_{60} / \mathrm{electrode}$ interfaces, leading to large charge carrier recombination and leakage currents $[33,37,38]$. Previous research has used $\mathrm{C}_{60}$ and $\mathrm{PC}_{60} \mathrm{BM}$ in combination wit h met al oxides or polymers as the ESLs, such as $\mathrm{TiO}_{2} / \mathrm{self}$ a ssembled monolayer $(\mathrm{SAM})-\mathrm{C}_{60}[39,40], \mathrm{ZnO} \mathrm{PC}_{60} \mathrm{BM}[41]$, pol yet hyl enimine $(\mathrm{PEI}) / \mathrm{PC}_{60} \mathrm{BM}[42]$ in the regular cell architecture to enhance the electron transfer. $\mathrm{PC}_{60} \mathrm{BM}$ and $\mathrm{C}_{60}$ alone can al so function as effective ESLs in bot $\mathrm{h}$ regular and inverted cell architectures [28, 32, 43]. However, $\mathrm{PC}_{60} \mathrm{BM}$ cannot be deposited by vacuumtechniques, whereas it is well known that $\mathrm{C}_{60}$ thin films can be deposited by thermal evaporation. So far, only solution-processed $\mathrm{C}_{60}$ as the ESL has been applied in perovskite solar cells with the regular cell architecture [32]. To achieve efficient cells, it would be advantageous if the deposition of the $\mathrm{C}_{60}$ and perovskite fil ms 
could be conducted sequentially without breaking vacuum, ensuring a high-qual it y interface between these two layers.

Figure $1 \mathrm{~b}$ shows the energy band diagram of our perovskite solar cells. On one hand, the lowest unoccupied molecular orbital (LUMO) 1 evel of $\mathrm{C}_{60}$ is slightly below the LUMO level of $\mathrm{CH}_{3} \mathrm{NH}_{3} \mathrm{PbI}_{3}$, allowing the smooth electron transfer from $\mathrm{CH}_{3} \mathrm{NH}_{3} \mathrm{PbI}_{3}$ to FTO. On the other hand, the highest occupied molecular orbital (HOMO) level of $\mathrm{C}_{60}$ is much lower than the HOMO level of $\mathrm{CH}_{3} \mathrm{NH}_{3} \mathrm{PbI}_{3}$, effectively blocking the holes from $\mathrm{CH}_{3} \mathrm{NH}_{3} \mathrm{PbI}_{3}$. $\mathrm{C}_{60}$ is therefore an ESL, reducing charge carrier recombinat ion and shunt currents.

Figure 2a shows the top-view scanning electron microscopy (SEM) image of an evaporated perovksite fil m on the $\mathrm{C}_{60}$-coated FTO substrate. The SEM image presents a uniformand compact surface wit h complete coverage and an average grain size of $150-200 \mathrm{~nm}$. On the cross-sectional SEM image (Figure S1, SI), a smooth perovskite film is shown with a thickness of a pproximately $320 \mathrm{~nm}$. Relatively thin perovskite layers are necessary in all-perovskite tandem solar cells in order to achieve current matching [44], which is hence our focus in this work. Such thin films can also generate respectable photocurrents. The surface topography of the perovskite film was measured by using tapping-mode atomic force microscope (AFM). Figure 2b shows the 3D image of the surface mor phology, demonstrating a root mean square (RMS) roughness of $15 \mathrm{~nm}$. Our vacuumprocessed perovskite layer is pinhole-free and sufficiently dense to 
prevent the penetration of spiro-OMeTAD through the perovskite layer to directly contact $\mathrm{C}_{60} /$ FTO electrode, thus avoiding any leakage. The absorption spectrum of the perovskite film is shown in Figure 2c, which exhibits a broad absorption ranging from 400 to 800 nm where an absorption tail occurs. The X-r ay diffraction patterns in Figure 2d confir m that the perovskite fil mis crystalline with the tet ragonal st ructure and r andom orient ation [27]. The peaks at $14.05^{\circ}$ and $28.3^{\circ}$ correspond to (110) and (220) planes. It is also found that a small amount of $\mathrm{PbI}_{2}$ (peak at $12.7^{\circ}$ ) present in our perovskite films can effectively benefit the device perfor mance and reproducibil it y a s reported previousl y [36].

In order to investigate the effect of $\mathrm{C}_{60}$ layer thickness on the device performance, the current density-voltage $(J-V)$ characteristics of the devices without $\mathrm{C}_{60}$ and with varying thicknesses of the $\mathrm{C}_{60}$ layer under AM1.5 G $100 \mathrm{~mW} / \mathrm{cm}^{2}$ il $1 \mathrm{uminat}$ ion are shown in Figure 3a. The perfor mance summary of corresponding devices is tabulated in Table $\boldsymbol{l}$ and the performance stat istics of these devices are shown in Figure $\boldsymbol{S} 2$ (SI). As a control, the device without $\mathrm{C}_{60}$ has a PCE of $4.4 \%$ with a $V_{\text {oc }}$ of $1.04 \mathrm{~V}$, a $J_{\text {sc }}$ of $9.4 \mathrm{~mA} / \mathrm{cm}^{2}$, and an FF of $44.7 \%$, exhibiting very poor performance and reproducibilit y due to ineffective electron extraction and hole blocking at the FTO/perovskite interface. This is evidenced by the low shunt resistance $\left(R_{\mathrm{sh}}\right)$ of $226 \Omega \mathrm{cm}^{2}$ and also the 1 arge leakage current under reverse bias as shown in the dark $J$-V characteristics (Figure S3b, SI). Al though a series resist ance $\left(R_{\mathrm{s}}\right)$ of $2.0 \Omega \mathrm{cm}^{2}$ is reached, the FF is quit e 1 ow. 
The devices with $\mathrm{C}_{60}$ inserted exhibit simultaneous enhancement of all primary performance parameters.

It is worth highlighting that the thermal evaporation technique is advantageous compared with the spin-coating technique since the materials can be evenly and uniformly coated on substrates, especially for an ultrathin layer, i.e. the deposition follows the surface topology of the substrates. Therefore, there is no distinct difference in the surface roughness (root mean square (RMS) roughness) between bare FTO and $\mathrm{C}_{60^{-}}$ coated FTO with various thicknesses, and simil ar mor phology occurs in all samples, as shown in Figure $\boldsymbol{S 4}(\boldsymbol{S I})$. A thickness variation of the $\mathrm{C}_{60}$ layer does not strongly influence the $V_{\text {oc }}$, however, remarkable changes of $J_{\text {sc }}$ and FF have been observed.

When a $2.5 \mathrm{~nm}$ thick $\mathrm{C}_{60}$ layer is inserted, the cell efficiency greatly increases to $13.4 \%$ with a $V_{\mathrm{oc}}$ of $1.05 \mathrm{~V}$, a $J_{\mathrm{sc}}$ of $18.0 \mathrm{~mA} / \mathrm{cm}^{2}$, and an FF of $71.1 \%$. Merely $2.5 \mathrm{~nm}$ thick $\mathrm{C}_{60}$ layer can effectively transfer electrons, block holes, and suppress charge recombination at the FTO/perovskite int erface, leading to a significant enhancement of $J_{\text {sc }}$ and FF. It s $R_{\mathrm{s}}$ decreases to 1.2 $\Omega \mathrm{cm}^{2}$ and $R_{\mathrm{sh}}$ increases to $1303 \Omega \mathrm{cm}^{2}$. With further increasing the thickness of the $\mathrm{C}_{60} 1$ ayer to $5.5 \mathrm{~nm}$, the FTO surface is completel y covered, evidenced by the continuous improvement in efficiency (Table 1) and device r epr oducibil it y (Figure S5, SI). The device wit h $5.5 \mathrm{~nm} \mathrm{C}_{60}$ a chieves a PCE of $14.9 \%$ with a $V_{\text {oc }}$ of $1.06 \mathrm{~V}$, a $J_{\text {sc }}$ of $18.3 \mathrm{~mA} / \mathrm{cm}^{2}$, and an $\mathrm{FF}$ of $77.0 \%$. To the best of our knowledge, such FFvalue is the highest among those reported for vacuum- 
deposited perovskite solar cells. This is primarily attributed to the minimized charge carrier recombination at the interface between the perovskite and $\mathrm{C}_{60}$ layer as well as the effective electron extraction, evidenced by 1 argely increased $R_{\mathrm{sh}}\left(2444 \Omega \mathrm{cm}^{2}\right)$ and small $R_{\mathrm{s}}\left(2.4 \Omega \mathrm{cm}^{2}\right)$. Compared with the devices without $\mathrm{C}_{60}$, the devices with $5.5 \mathrm{~nm} \mathrm{C}_{60}$ have negligibly low current under reverse bias, as shown in the dark $J-V$ characteristics (Figure S3b, SI). This is at tributed to the efficient hole blocking by the $\mathrm{C}_{60}$ layer.

Thicker $\mathrm{C}_{60} 1$ ayers $(10$ and $15 \mathrm{~nm}$ ) lead to a reduction in device efficiency, primarily due to the decreased $J_{\mathrm{sc}}$ and FF (for the cell with $10 \mathrm{~nm} \mathrm{C} 60$ : $R_{\mathrm{s}}=2.6$ $\Omega \mathrm{cm}^{2}$ and $R_{\mathrm{sh}}=2599 \Omega \mathrm{cm}^{2}$; for the cell with $15 \mathrm{~nm} \mathrm{C}_{60}: R_{\mathrm{s}}=3.0 \Omega \mathrm{cm}^{2}$ and $R_{\mathrm{sh}}=$ $2811 \Omega \mathrm{cm}^{2}$ ). It should be noted that $\mathrm{C}_{60}$ has a band gap of $1.7 \mathrm{eV}$, causing excessive $1 \mathrm{ight}$ loss if the layer is too thick, as shown in Figure 4. The $\mathrm{C}_{60}$ layers with 2.5 and $5.5 \mathrm{~nm}$ have higher transmit ance throughout the spectral range; however, the thick $\mathrm{C}_{60} 1$ ayers with 10 and $15 \mathrm{~nm}$ have significant light absorption from 350 to $550 \mathrm{~nm}$, which decreases the incident light $\mathrm{reaching} \mathrm{the}$ per ovskite 1 ayer and leads t o the reduct ion in $J_{\text {sc }}$. Moreover, with the increase of $\mathrm{C}_{60}$ layer thickness, $R_{\mathrm{s}}$ is increased correspondingly due to the relatively 1 ow electron mobility in $\mathrm{C}_{60}$ compared with inorganic metal oxides [35], resulting in excess $R_{\mathrm{s}}$ and slight ly reduced FF.

Figure $3 b$ shows the external quantum efficiency (EQE) spectra of perovskite cell s incorporating various thickness of $\mathrm{C}_{60}$ layers with as the 
ESLs. The devices with 2.5 and $5.5 \mathrm{~nm}$ thick $\mathrm{C}_{60} 1$ ayers exhibit higher EQE values than those with 10 and $15 \mathrm{~nm} \mathrm{C}_{60}$ due to the 1 ight 1 oss caused by absorption of thick $\mathrm{C}_{60} 1$ ayers in the $\mathrm{r}$ ange of $350-550 \mathrm{~nm}$, demonstrated by the transmittance spectra shown in Figure 4. The device with a $5.5 \mathrm{~nm}$ thick $\mathrm{C}_{60}$ possesses the highest EQE, producing an EQE-int egrated $J_{\mathrm{sc}}$ of $18.3 \mathrm{~mA} / \mathrm{cm}^{2}$, in good agreement with $J_{\mathrm{sc}}$ from the $J-V$ curve. It is interest ing that all EQE curves of our evaporated perovskite solar cells present an obvious dip ranging from 650 to $750 \mathrm{~nm}$, which is likely ascribed to optical cavity effect [28]. Therefore, the photocurrent of our vapor-assisted perovskite solar cells can be further enhanced by careful photon management.

To evaluate the reproducibil ity of our devices using an ultrathin $\mathrm{C}_{60}$ as the electron-selective 1 ayer, 30 devices wit h $5.5 \mathrm{~nm} \mathrm{C}_{60} 1$ ayers in several batches were fabricated. As shown in the histogram of the corresponding device dat a in Figure S5, the average PCE for these devices is $14.3 \%$ and the highest PCE is $15.3 \%$. Therefore, our cells using the ultrathin $\mathrm{C}_{60}$ interface layers and evaporated perovskite absorbers appear to have good reproducibil it y.

One of the crucial issues of perovskite solar cells is the hysteresis in $J$-V curves, which leadsto a strong dependence of device performance on the voltage scanning direction, the scanning rate, and the device architecture [45]. Such hysteresis is likely to overestimate the device performance. Figure 5a shows the $J-V$ characterist ics of the device with 5.5 $\mathrm{nm} \mathrm{C}_{60}$ as $\mathrm{t}$ he ESL under $100 \mathrm{~mW} / \mathrm{cm}^{2}$ il 1 umination a ppl $\mathrm{y}$ ing different $\mathrm{vol} \mathrm{tage}$ 
scanning directions. It can be seen that our devices exhibit very small hysteresis, producing a rever se-for ward PCE of $14.9 \%$ with a $V_{\text {oc }}$ of $1.06 \mathrm{~V}$, a $J_{\mathrm{sc}}$ of $18.3 \mathrm{~mA} / \mathrm{cm}^{2}$, and an FF of $77.0 \%$ and a forward-reverse PCE of $14.1 \%$ with a $V_{\text {oc }}$ of $1.06 \mathrm{~V}$, a $J_{\text {sc }}$ of $18.1 \mathrm{~mA} / \mathrm{cm}^{2}$, and an FF of $73.7 \%$. To evaluate the accuracy of device perfor mance, the steady-st at e efficiency measurement is a reliable method that reflects the actual performance under oper at ion. Figure 5b shows the st eady-st at e $J_{\text {sc }}$ and PCE of the device wit h 5.5 $\mathrm{nm} \mathrm{C}_{60}$ as the ESL at a constant bias of $0.861 \mathrm{~V}$ under AM1.5 G $100 \mathrm{~mW} / \mathrm{cm}^{2}$ il $1 \mathrm{uminat}$ ion. A steady-st at e $J_{\mathrm{sc}}$ of a pproximately $17 \mathrm{~mA} / \mathrm{cm}^{2}$ and st abil ized out put power of $14.6 \%$ is achieved. The hysteresis and steady-st at e dat a for devices with $10 \mathrm{~nm} \mathrm{C} 60$ as the ESL are al so shown in Figure S6 (SI). However, the devices without a $\mathrm{C}_{60} 1$ ayer have serious hysteresis in the $J$ - $V$ curves (Figure S3a, SI). Our result s on significant ly reduced hysteresis and steadystate efficeincy close to $J$ - $V$ efficiency indicate that our evaporated perovskite fil ms not only have a compact structure with low densit ies of defects that could trap electrons and holes [4], but also have good interfacial contact to the $\mathrm{C}_{60} 1$ ayer with surface passivation [43].

To understand the charge carrier recombination in the devices wit h $\mathrm{C}_{60}$ as the ESL, the $J-V$ characteristics were measured under different 1 ight intensities ranging from 1 to $100 \mathrm{~mW} / \mathrm{cm}^{2}$, as shown in Figure 6a. Figure 6b shows the power law dependence of $J_{\text {sc }}$ on light intensity $\left(J \propto I^{a}\right)$, which exhibits a linear relation on a double logarithmic scale with $\alpha=0.99$. A solar cell with no space charge effect will have an $\alpha$ value close to 1 [4648]. Therefore, our devices with $\mathrm{C}_{60}$ as the ESL do not appear to be space 
charge 1 imt ed. In contrast, the devices without $\mathrm{C}_{60}$ have a 1 inear rel at ion with $\alpha=1.20$, indicating significant space charge buil t-up in the devices and charge carrier losses occur as shown in Figure $\boldsymbol{S 7}$ (SI) [49-52]. Figure 6c show s $V_{\text {oc }}$ as a function of 1 ogar ithmic 1 ight intensity. $V_{\text {oc }}$ appears to increase monotonically with logarithmic light intensity, indicating that trapassisted Shockley-Read-Hall recombination is prevalent in $\mathrm{C}_{60}$-based perovskite solar cells $[36,49]$. The dependence of FF on 1 ight intensity is shown in Figure 6d. A maximum FF of $77.9 \%$ is reached at $20 \mathrm{~mW} / \mathrm{cm}^{2}$, impl ying that the charge carrier recombination is minimal at a relatively lower light intensity due to the low carrier concentration generated. The results suggest that an ultrathin 1 ayer of $\mathrm{C}_{60}$ can efficient 1 yextract the chargecarriers and suppress the charge recombination.

Figure 7 compares the charge carrier lifetime as measured by transient photoluminescence (TRPL) in perovskite deposited on FTO to that in perovskite deposited on $\mathrm{FTO}_{6} \mathrm{C}_{60}$. The TRPL decay curves were fitted assuming a bi-exponential decay model. For the FTO/perovskite sample, $\tau_{1}$ is $14.9 \mathrm{~ns}(44.1 \%)$ and $\tau_{2}$ is $75.9 \mathrm{~ns}(55.9 \%)$, leading to a weighted average of a pproximatel y $49.0 \mathrm{~ns}$. For the $\mathrm{FTO} / \mathrm{C}_{60} /$ per ovskite sample, $\tau_{1}$ is $2.0 \mathrm{~ns}(74.5 \%)$ and $\tau_{2}$ is $8.7 \mathrm{~ns}(25.5 \%)$ wit h a weighted average of a pproximatel y $3.7 \mathrm{~ns}$. Thus, it is clear that the insertion of a thin $\mathrm{C}_{60}$ layer greatly enhances the electron extraction at the perovskite/FTO interface. This is consistent with the device characteristics discussed above. 
By opt imizing the thickness of spir o-OMeTAD layer, the maximum PCE of our cells can reach $15.7 \%$ with a $V_{\text {oc }}$ of $1.10 \mathrm{~V}$, a $J_{\text {sc }}$ of $18.9 \mathrm{~mA} / \mathrm{cm}^{2}$, and an FF of 75.4\%. It s $J-V$ character ist ics and EQE spectrum are shown in Figure 8 . The EQE-integrated $J_{\text {sc }}$ can reach $18.5 \mathrm{~mA} / \mathrm{cm}^{2}$, close to that from $J-V$ curve. It s steady-state photocurrent and efficiency at a bias of $0.906 \mathrm{~V}$ are shown in

Figure S8. Mor eover, the dip of EQE spectrum shift s to blue range slight ly due to the cavity effect by the spiro-OMeTAD thickness variation.

We find that thermally evaporated fullerene $\mathrm{C}_{70}$ can also act as the ESLs in our vacuum-processed regular perovskite solar cells. As 1 ist ed in Table 1, the device with $5.5 \mathrm{~nm} \mathrm{C}_{70}$ shows a PCE of $14.9 \%$ with a $V_{\text {oc }}$ of $1.03 \mathrm{~V}$, a $J_{\text {sc }}$ of 18.6 $\mathrm{mA} / \mathrm{cm}^{2}$, and an FF of $77.7 \%$, as shown in Figure $\mathbf{5 9 a}$. It s EQE spectrum is al so shown in Figure S9b. The $J_{\text {sc }}$ of the cells wit h $C_{70}$ ESLs is slight ly higher than that of the cells with $\mathrm{C}_{60}$ ESLs, which is due to the fact that $\mathrm{C}_{70}$ has a slight 1 y 1 arger band gap $(2.0 \mathrm{eV})$ than $\mathrm{C}_{60}(1.7 \mathrm{eV})$, 1 eading to 1 ess 1 ight 1 oss. Therefore, there is still room to enhance our annealing-free vacuumprocessed regular perovskite solar cells.

\section{Conclusion}

We have demonstrated high-efficiency vacuum-processed regular perovskite solar cells with an ultrathin metal-oxide-free and annealingfree $\mathrm{C}_{60}$ or $\mathrm{C}_{70}$ as the electron-selective layer. The devices with $\mathrm{C}_{60}$ interfacial layers exhibit high fill factors and high performance, which can be attributed to minimal recombination and fast electron extraction at the interface between the perovskite and $\mathrm{C}_{60} 1$ ayers. The $\mathrm{C}_{60} 1$ ayer not 
only serves as a hole blocking layer and an electron-selective contact but also it forms an intimate contact with the perovskite layer and promotes the growth of a well crystallized film. Light intensity dependent characteristics and TRPL results indicate increased charge carrier transfer at the interface, leading to a maximumefficiency of $15.7 \%$ and a steady-state efficiency of $14.6 \%$. With the realization of efficient cells, the annealing-free vacuum deposition of perovskite absorbers and fullerenes ESLs shows its promise for fabricat ing all-perovskite tandem solar cells on flexible substrates.

\section{Acknowledgment}

The work at The University of Toledo is supported by the U.S. Department of Energy (DOE) SunShot Initiative under the Next Generation Photovoltaics 3 program (DE-FOA-0000990) and the Ohio Research Scholar Program. The work at the National Renewable Energy Laboratory is supported by the U.S. Department of Energy under Contract No. DE-AC36-08GO28308. MY and KZ acknowledge support by the U.S. Department of Energy (DOE) SunShot Init iative under the Next Generation Photovoltaics 3 progr a m (DE-FOA-0000990). H.M.Z thanks the support from the 973 Progr a m of Chin a (2015CB932203).

\section{References}


[1] G. Xing, N. Ma thews, S. Sun, S.S. Lim, Y.M. La m, M. Gr ät zel, S. Mha is a 1 ka r, T.C. Su m, Sc ien ce, 342 (2013) 344-347.

[2] S.D. Stranks, G.E. Eper on, G. Grancini, C. Menela ou, M.J.P. Al cocer, T. Leijt en s, L.M. Her z, A. Pet r ozza, H.J. Sn a it h, Scien ce, 342 (2013) 341-344.

[3] W.-J. Yin, T. Shi, Y. Ya n, Adv. Ma t er ., 26 (2014) 4653-4658.

[4] W.-J. Yin, T. Shi, Y. Ya n, Appl . Ph y s. Let t ., 104 (2014) 063903

[5] P. Doc a mpo, J.M. Ba 1 1, M. Da r wich, G.E. Eper o n, H.J. Sn a it h, Nat Commun, 4 (2013) 2761.

[6] J. Bisquer t , J. Phy s. Chem. Let t ., 4 (2013) 2597-2598.

[7] G. Hodes, Science, 342 (2013) 317.

[8] A. Kojima, K. Teshima, Y. Shir a i, T. Miy a sa ka, J. Am. Chem. Soc., 131 (2009) 6050-6051.

[9] H.-S. Kim, C.-R. Lee, J.-H. Im, K.-B. Lee, T. Moeh1, A. Mar chior o, S.-J. Moon, R. Hu mphr y -Ba ker, J.-H. Yu m, J.E. Moser, M. Gr at zel, N.-G. Pa r k, Sci. Rep., 2 (2012) 591.

[10] N.G. Pa r k, J. Am. Chem. So c ., 4 (2013) 2423.

[11] W.S. Ya ng, J.H. Noh, N.J. Jeon, Y.C. Kim, S. Ry u, J. Seo, S.I. Seok, Science, 348 (2015) 1234-1237.

[12] H. Zhou, Q. Chen, G. Li, S. Luo, T.-b. Song, H.-S. Dua n, Z. Hong, J. You, Y. Liu, Y. Yang, Science, 345 (2014) 542-546.

[13] W. Ke, G. Fang, J. Wa n, H. Ta o, Q. Liu, L. Xiong, P. Qin, J. Wang, H. Lei, G. Yang, M. Qin, X. Zha o, Y. Ya n, Na t Commun, 6 (2015) 6700.

[14] Y. Zh a o, K. Zh u, J. Am. Chem. So c., 136 (2014) 12241.

[15] Y. Zha o, K. Zhu, J. Ph y s. Chem. C, 118 (2014) 9412.

[16] T. Todorov, T. Gershon, O. Gunawan, C. St urdevant, S. Guha, Appl. Phys. Let t ., 105 (2014) 173902.

[17] C.D. Bail ie, M.G. Chr ist of or o, J.P. Ma il oa, A.R. Bowr ing, E.L. Unger, W.H. Nguyen, J. Bur schka, N. Pell et, J.Z. Lee, M. Gr at zel, R. Noufi, T. Buonassisi, A. Sa 11 eo, M.D. Mc Gehee, Ener gy Envir on. Sci., 8 (2015) 956-963.

[18] L. Kranz, A. Abat e, T. Feur er, F. Fu, E. Ava ncini, J. Löckinger, P. Reinhard, S.M. Za keer u dd in, M. Gr ät zel, S. Buechel er, A.N. Tiwa r i, J. Phy s. Chem. Let t ., 6 (2015) 2676-2681. 
[19] M. He, D. Zheng, M. Wa ng, C. Lin, Z. Lin, J. Ma t er . Chem. A, 2 (2014) 5994-6003.

[20] T. Zhang, M. Yang, Y. Zha o, K. Zh u, Na n o Let t ., 15 (2015) 3959-3963.

[21] D. Liu, T.L. Kel 1 y, Nat Phot on, 8 (2014) 133.

[22] W. Ke, G. Fang, Q. Liu, L. Xiong, P. Qin, H. Ta o, J. Wang, H. Lei, B. Li, J. Wa n, G. Yang, Y. Ya n, J. Am. Chem. So c., 137 (2015) 6730-6733.

[23] Q. Hu, J. Wu, C. Jiang, T. Liu, X. Que, R. Zhu, Q. Gong, ACS Na n o, 8 (2014) 1016110167.

[24] Z. Xia o, C. Bi, Y. Sha o, Q. Dong, Q. Wang, Y. Yua n, C. Wang, Y. Ga o, J. Hu ang, Ener gy Envir on. Sci., 7 (2014) 2619-2623.

[25] M. Liu, M.B. John st on, H.J. Sn a it h, Na t u r e, 501 (2013) 395-398.

[26] O. Mal inkiewicz, C. Roldán-Carmona, A. Soriano, E. Bandiello, L. Ca ma cho, M.K. Na zeer uddin, H.J. Bol in k, Adv. Ener g y Ma t er ., 4 (2014) 1400345.

[27] O. Mal inkiewicz, A. Yell a, Y.H. Lee, G.M. Espall a r gas, M. Gr a et zel, M.K. Na zeer udd in, H.J. Bol ink, Na t . Phot on ., 8 (2014) 128-132.

[28] Q. Lin, A. Ar min, R.C.R. Na gir i, P.L. Bur n, P. Mer edit h, Nat Phot on, 9 (2015) 106-112.

[29] M.R. Ley den, L.K. On o, S.R. Ra ga, Y. Ka t o, S. Wa ng, Y. Qi, J. Ma t er . Chem. A, 2 (2014) 18742-18745.

[30] L.K. Ono, S. Wang, Y. Kat o, S.R. Raga, Y. Qi, Energy Envir on. Sci., 7 (2014) 3989-3993.

[31] C.-W. Chen, H.-W. Kang, S.-Y. Hsia o, P.-F. Yang, K.-M. Chiang, H.-W. Lin, Adv . Ma t er ., 26 (2014) 6647-6652.

[32] K. Wojciechowski, T. Leijt ens, S. Siprova, C. Schl uet er , M.T. Hör a nt ner , J.T.-W. Wa ng, C.-Z. Li, A.K.Y. Jen, T.-L. Lee, H.J. Sn a it h, J. Ph y s. Chem. Let t ., (2015) 2399-2405.

[33] D.W. Zha o, X.W. Sun, C.Y. Jiang, A.K.K. Kyaw, G.Q. Lo, D.L. Kwong, Appl . Phy s. Let t ., 93 (2008) 083305.

[34] D.W. Zhao, W.H. Tang, L. Ke, S.T. Tan, X.W. Sun, ACS Appl. Mater . In t er faces, 2 (2010) 829-837.

[35] P.-W. Liang, C.-C. Chu eh, S.T. Wil 1 ia ms, A.K.Y. Jen, Adv. Ener gy Mat er ., 5 (2015) 1402321. 
[36] D. Zhao, M. Sexton, H.-Y. Park, G. Baure, J.C. Nino, F. So, Adv. Energy Ma t er ., 5 (2015) 1401855.

[37] P. Peumans, A. Yakimov, S.R. For rest , J. Appl . Ph y s., 93 (2003) 3693-3723.

[38] F.J. Zhang, D.W. Zha o, Z.L. Zhuo, H. Wang, Z. Xu, Y.S. Wang, Sol. Energy Ma t er . Sol . Cel1 s, 94 (2010) 2416-2421.

[39] A. Abr u sci, S.D. St r a nk s, P. Do c a mpo, H.-L. Yip, A.K.Y. Jen, H.J. Sn a it h, Na no Let $t$., 13 (2013) 3124-3128.

[40] K. Wojciechowski, S.D. Stranks, A. Abate, G. Sadoughi, A. Sadhanala, N. Ko pid a kis, G. Ru mbl es, C.-Z. Li, R.H. Fr iend, A.K.Y. Jen, H.J. Sna it h, ACS Na no, 8 (2014) 12701-12709.

[41] J. Kim, G. Kim, T.K. Kim, S. Kwo n, H. Ba ck, J. Lee, S.H. Lee, H. Kang, K. Lee, J. Ma t er. Chem. A, 2 (2014) 17291-17296.

[42] S. Ry u, J. Seo, S.S. Shin, Y.C. Kim, N.J. Jeon, J.H. Noh, S.I. Seo k, J. Ma t er . Chem. A, 3 (2015) 3271-3275.

[43] Y. Sh a o, Z. Xia o, C. Bi, Y. Yua n, J. Huang, Na t Commun, 5 (2014).

[44] D.W. Zha o, L. Ke, Y. Li, S.T. Ta n, A.K.K. Ky a w, H.V. Demir, X.W. Sun, D.L. Car r ol 1, G.Q. Lo, D.L. Kw ong, Sol. Ener gy Ma t er. Sol . Cel 1 s, 95 (2011) 921-926.

[45] H.J. Sna it h, A. Abat e, J.M. Bal1, G.E. Eper on, T. Leijt en s, N.K. Noel, S.D. St r a nks, J.T.-W. Wang, K. Wojciechowski, W. Zhang, J. Phys. Chem. Let t., 5 (2014) 1511-1515.

[46] D. Bi, L. Yang, G. Boschl oo, A. Hagfel dt, E.M.J. Johansson, J. Phys. Chem. Let t ., 4 (2013) 1532-1536.

[47] L.J.A. Ko st er, V.D. Miha il et chi, H. Xie, P.W.M. Bl om, Appl . Phy s. Let t ., 87 (2005) 203502.

[48] V.D. Mihail et chi, J. Wil deman, P.W.M. Bl om, Phys. Rev. Let t., 94 (2005) 126602.

[49] Y. Liu, Z. Hong, Q. Chen, W. Chang, H. Zhou, T.-B. Song, E. Young, Y. Yang, J. You, G. Li, Na no Let t ., 15 (2015) 662-668.

[50] L. Wang, C. McCl eese, A. Koval sky, Y. Zha o, C. Bur da, J. Am. Chem. Soc., 136 (2014) 12205-12208.

[51] Q. Chen, H. Zhou, T.-B. Song, S. Luo, Z. Hong, H.-S. Dua n, L. Dou, Y. Liu, Y. Yang, Na no Let t ., 14 (2014) 4158-4163. 
[52] T. Supasai, N. Rujisa mphan, K. Ul $1 \mathrm{r}$ ich, A. Chemseddine, T. Dit t r ich, Appl . Phy s. Let t ., 103 (2013) 183906 

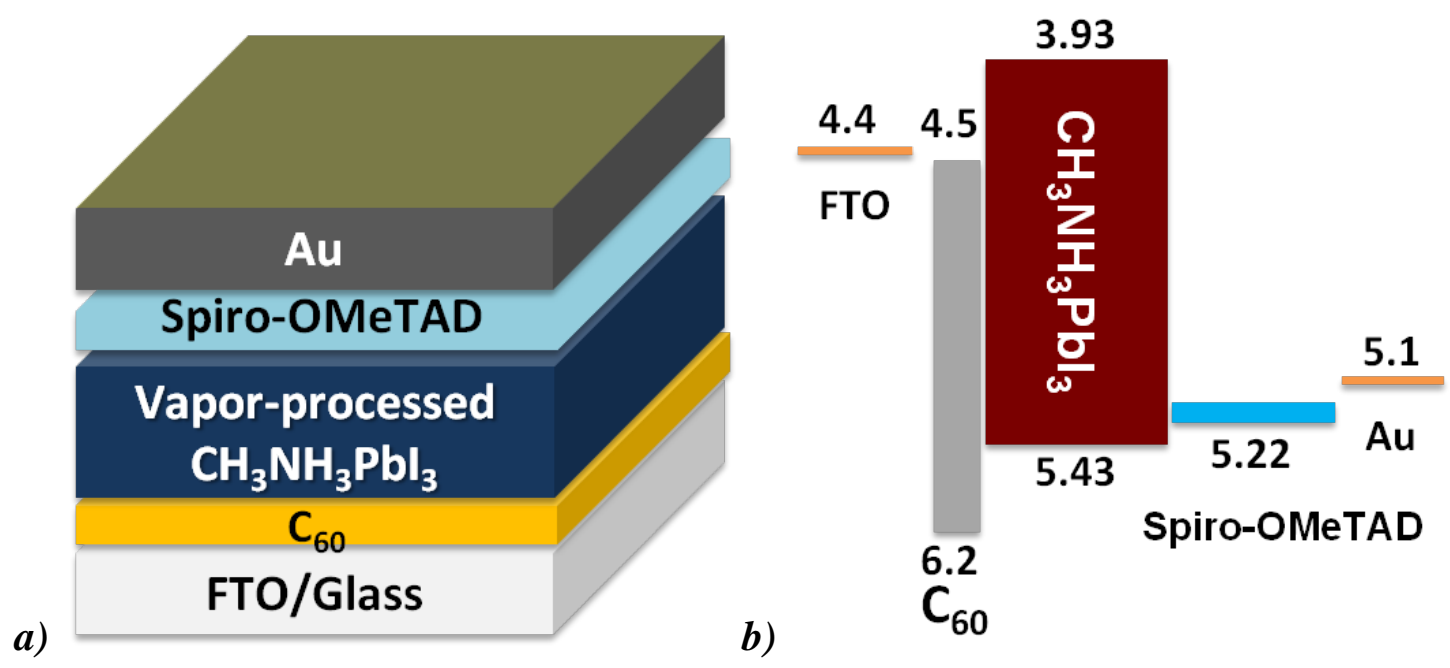

Figure 1. (a) Device structure and (b) Energy band diagram of our perovskit e sol ar cells with $\mathrm{C}_{60}$ as the ESLs. 

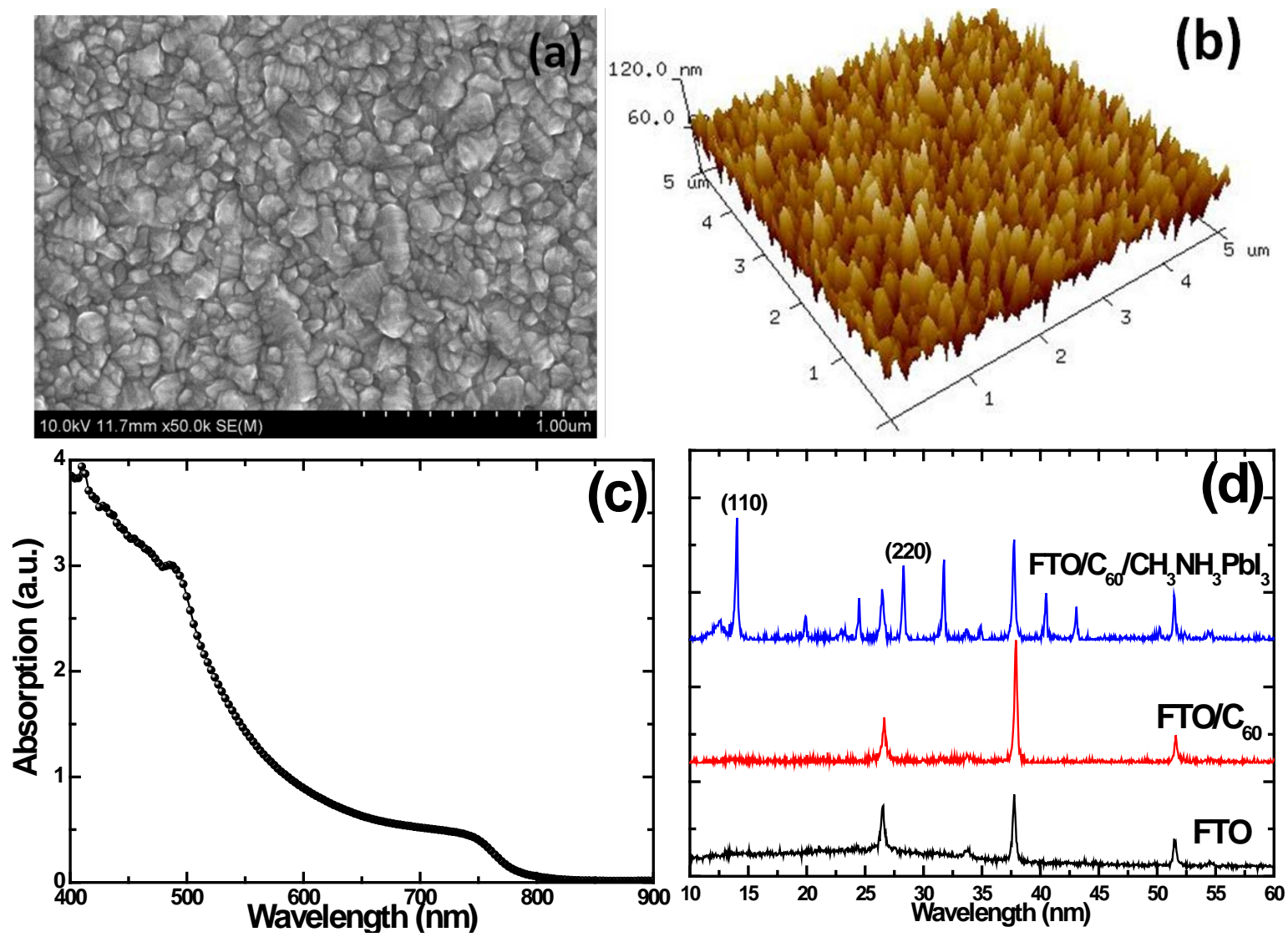

Figure 2. (a) SEM image and (b) tapping-mode AFM image of an evaporated perovskite film on a $\mathrm{C}_{60}$-deposited FTO substrate, (c) UV-Vis absorption spectrum of the perovskite film, and (d) X-ray diffraction patterns for perovskite films on $\mathrm{C}_{60}$-coated FTO along with FTO and $\mathrm{C}_{60}$-coated FTO patterns for reference. 

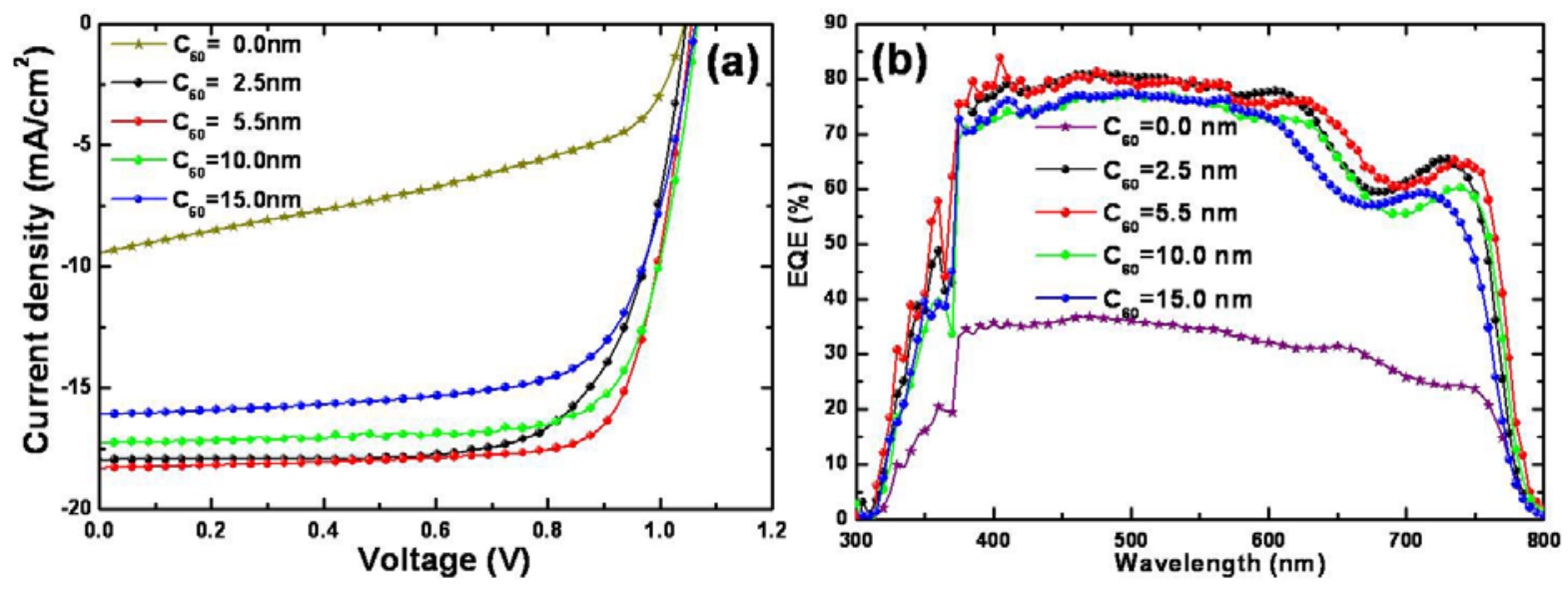

Figure 3. (a) $J-V$ char act er ist ic s under AM1.5G $100 \mathrm{~mW} / \mathrm{cm}^{2}$ il $1 \mathrm{u}$ minat ion and (b) EQE spectra of perovskite solar cells with varying $\mathrm{C}_{60} l$ ayer thickness. 


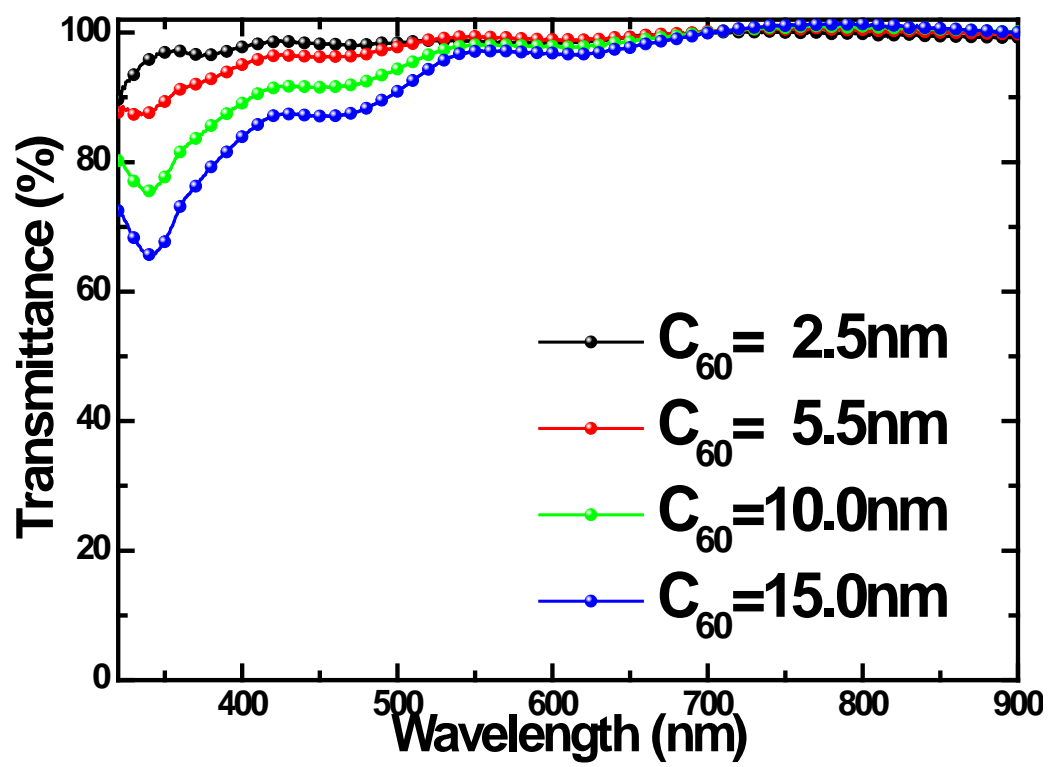

Figure 4. Tr ansmit t ance spect $\mathrm{r}$ a of $\mathrm{C}_{60} \mathrm{l}$ a yer $\mathrm{s}$ wit h different thickness. 

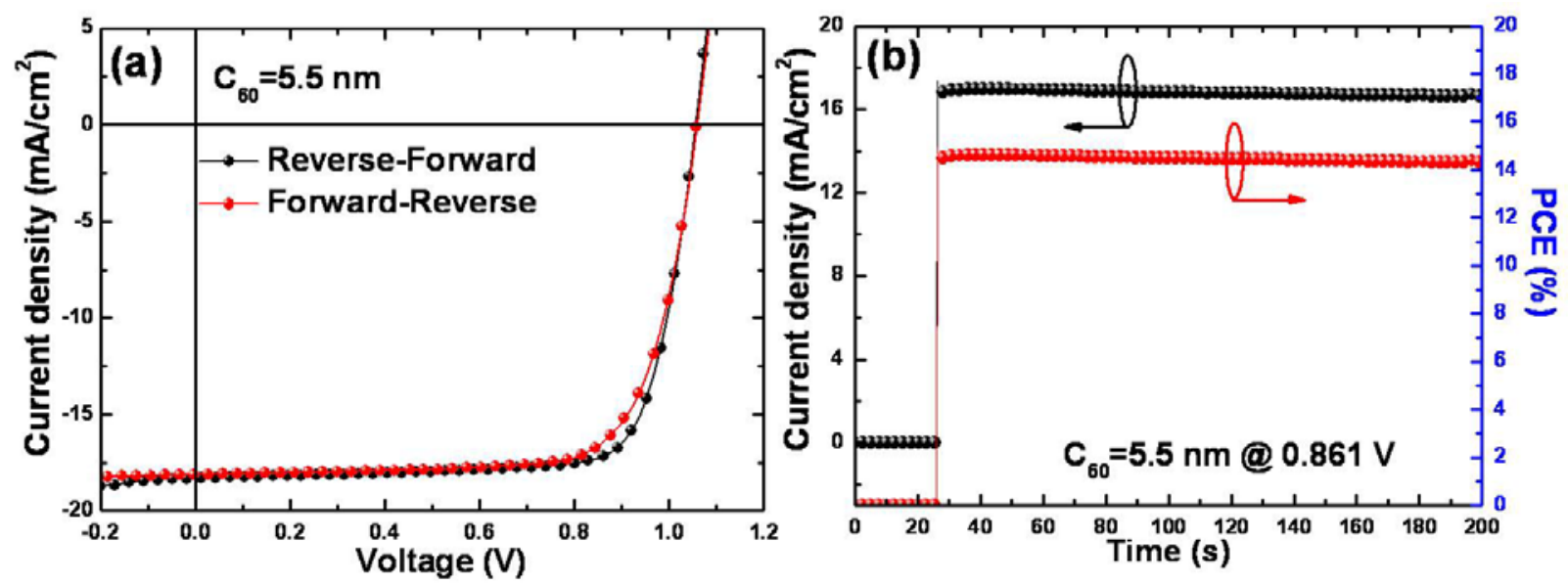

Figure 5. (a) $J-V$ characteristics of the device with $5.5 \mathrm{~nm} \mathrm{C}_{60}$ as electronselective layer under $100 \mathrm{~mW} / \mathrm{cm}^{2}$ il $1 \mathrm{umination}$ under different voltage scanning direction: Reverse-Forward and Forward-Reserse and (b) Steadystate $J_{\text {sc }}$ and PCE of the device with $5.5 \mathrm{~nm} \mathrm{C}_{60}$ as the electron-selective layer at a constant bias of $0.861 \mathrm{~V}$ under $100 \mathrm{~mW} / \mathrm{c} \mathrm{m}^{2}$ il $1 \mathrm{uminat}$ ion. 

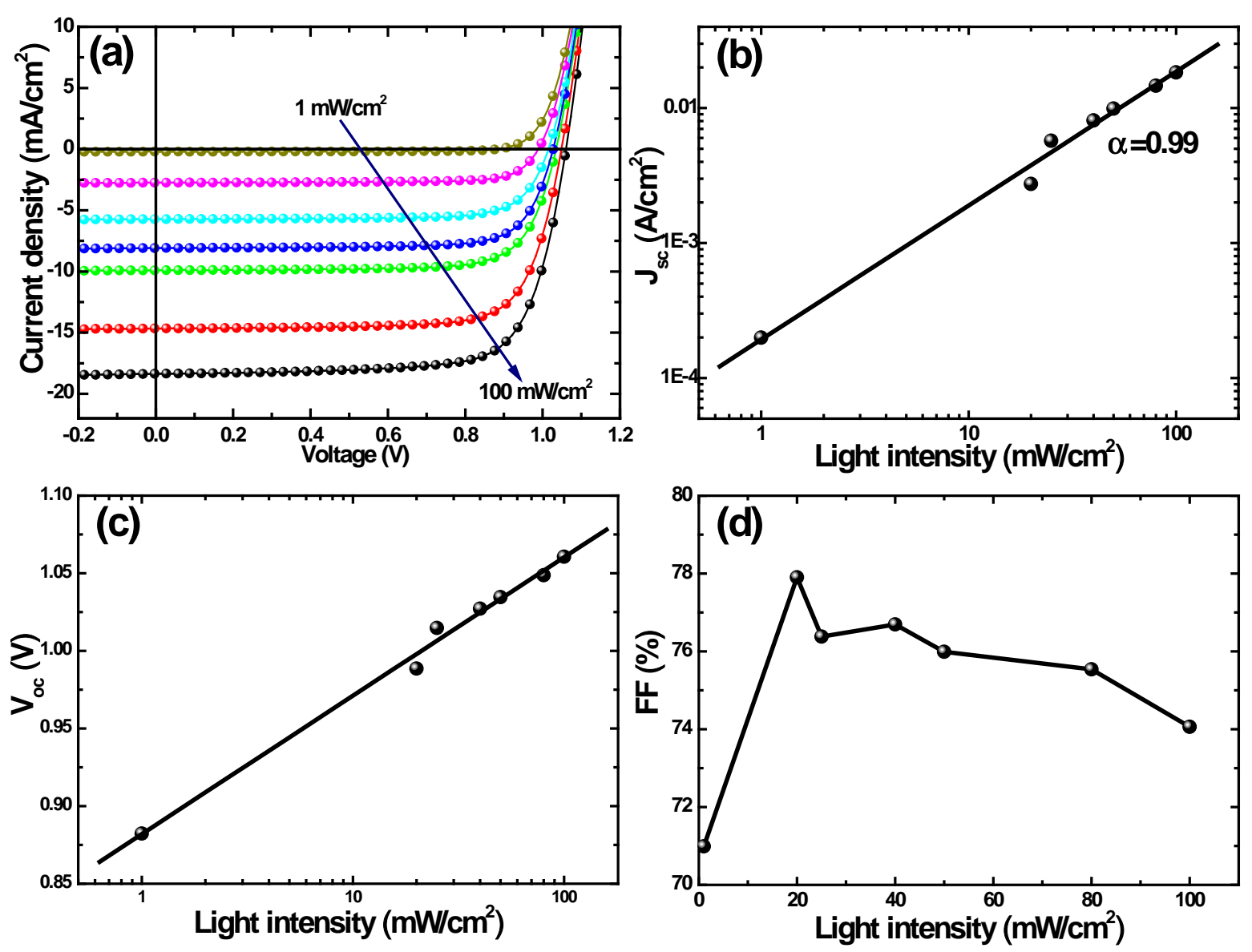

Figure 6. Light -intensit y dependence of perovskite solar cell performance wit h $5.5 \mathrm{~nm} \mathrm{C}_{60}$ as the el ectron-sel ect ive 1 ayer: (a) $J-V$ char acter ist ics, (b) $J_{\text {sc }}$ versus light intensity, (c) $V_{\text {oc }}$ versus 1 ight int ensity and (d) $F F$ versus 1 ight intensity. The 1 ight intensity ranges from $1 \mathrm{~mW} / \mathrm{cm}^{2}$ to $100 \mathrm{~mW} / \mathrm{cm}^{2}$ 


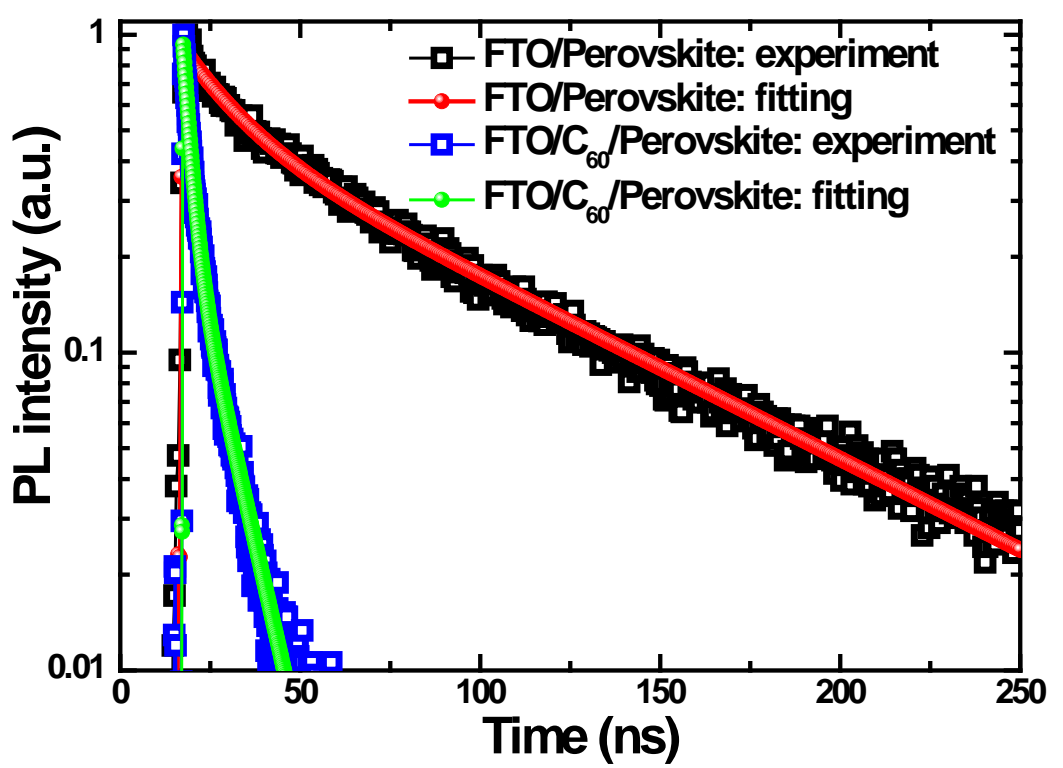

Figure 7. Transient photoluminescence (TRPL) measurements comparing charge carrier lifetime in the perovskite films deposited on FTO and on $\mathrm{FTO} / \mathrm{C}_{60}(5.5 \mathrm{n} \mathrm{m})$. 

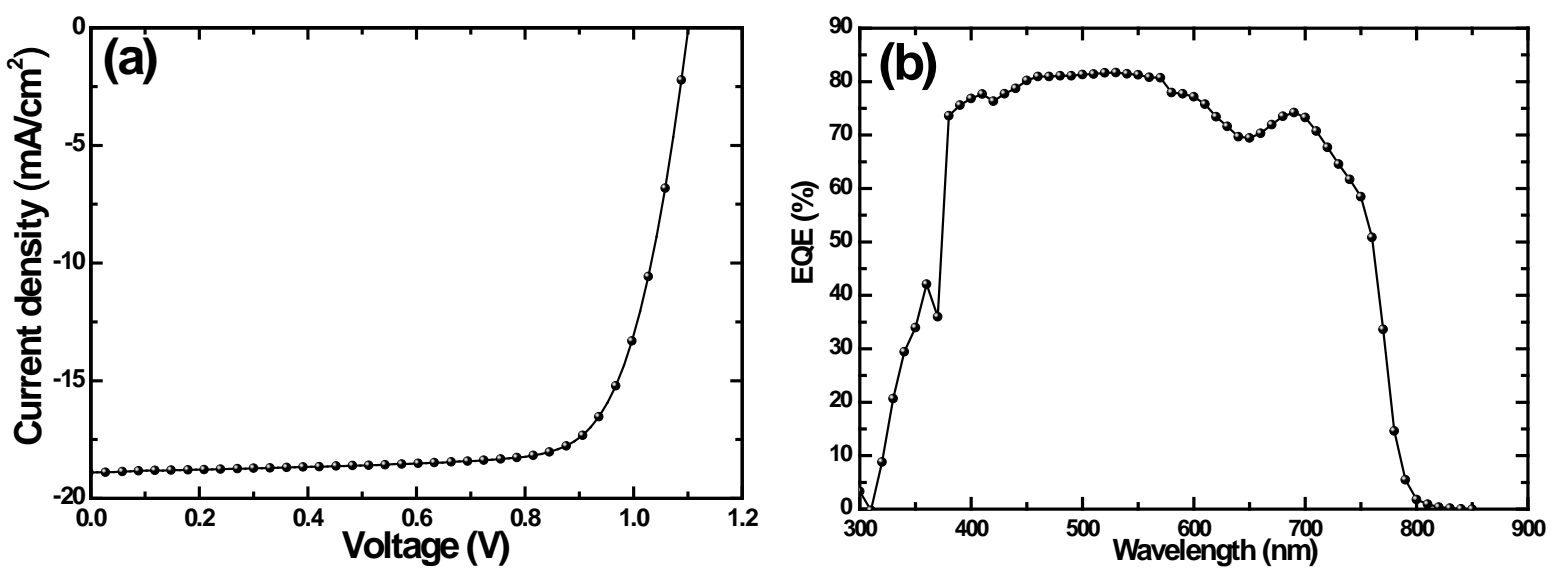

Figure 8. (a ) $J-V$ character ist ic under AM1.5G $100 \mathrm{~mW} / \mathrm{c} \mathrm{m}^{2}$ il $1 \mathrm{uminat}$ ion and (b) EQE spectrum of our best-performing perovskite solar cells with $5.5 \mathrm{~nm} \mathrm{C}_{60}$ a s the ESL. 
Table 1. Summary of performance metrics of the devices with varying thicknesses of $\mathrm{C}_{60} 1$ ayer as the ESL and with $5.5 \mathrm{~nm} \mathrm{C}_{70}$ as the ESL.

\begin{tabular}{rcccc}
\hline & $\begin{array}{c}J_{\mathrm{sc}} \\
{\left[\mathrm{mA} \mathrm{c} \mathrm{m}^{-2}\right]}\end{array}$ & $\begin{array}{c}V_{\mathrm{oc}} \\
{[\mathrm{V}]}\end{array}$ & $\begin{array}{c}\text { FF } \\
{[\%]}\end{array}$ & $\begin{array}{c}\text { PCE } \\
{[\%]}\end{array}$ \\
\hline $\mathrm{C}_{60}=0.0 \mathrm{n} \mathrm{m}$ & 9.4 & 1.04 & 44.7 & 4.4 \\
$\mathrm{C}_{60}=2.5 \mathrm{~nm}$ & 18.0 & 1.05 & 71.1 & 13.4 \\
$\mathrm{C}_{60}=5.5 \mathrm{n} \mathrm{m}$ & 18.3 & 1.06 & 77.0 & 14.9 \\
$\mathrm{C}_{60}=10.0 \mathrm{n} \mathrm{m}$ & 17.3 & 1.07 & 75.2 & 13.9 \\
$\mathrm{C}_{60}=15.0 \mathrm{~nm}$ & 16.1 & 1.06 & 70.4 & 12.0 \\
$\mathrm{C}_{70}=5.5 \mathrm{~nm}$ & 18.6 & 1.03 & 77.7 & 14.9 \\
\hline
\end{tabular}


Dewei Zhao is a postdoctoral associate in Wright Center for Photovoltaics Innovation and Commercialization and Department of Physics and Astronomy at The University of Toledo. He received his Ph.D. degree in electrical engineering from Nanyang Technological University, Singapore in 2011. He joined Prof Yanfa Yan's group in 2014. His recent research is focused on vacuum-processed and solutionprocessed perovskite solar cells, including material synthesis, device fabrication/characterization, as well as organic optoelectronics such as solar cells and light-emitting diodes.

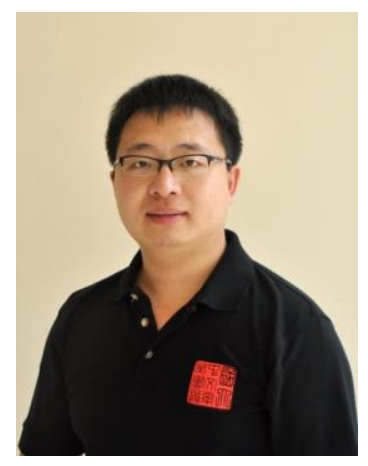

Weijun Ke is a Ph.D. student at School of Physics and Technology, Wuhan University. Currently, he is also a visiting scholar supervised by Prof. Yanfa Yan in the Department of Physics and Astronomy and Wright Center for Photovoltaics Innovation and Commercialization at The University of Toledo. His main research interest is perovskite solar cells.

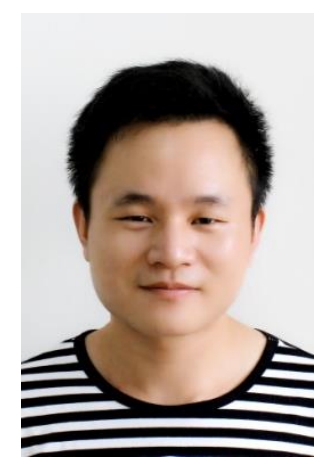

Corey R. Grice received his Bachelor of Science in engineering degrees in Chemical Engineering and Materials Science \& Engineering from the University of Michigan in 2005 . From 2005 until 2011 he worked in the private sector, primarily in fuel cell research and development. He entered graduate school at the University of Toledo in 2011 and completed a Professional Science Masters degree in Physics with specialization in photovoltaics in 2013. He is currently pursuing a PhD in Physics under the guidance of Dr. Yanfa Yan, with research focusing on various novel and low cost thin film photovoltaic and photoelectrochemical devices. 


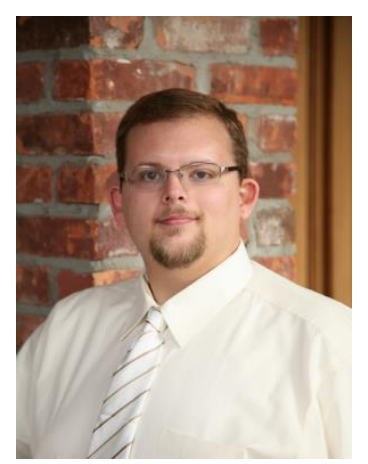

Alexander J Cimaroli received a B.S. in Applied Physics from Purdue University, West Lafayette, Indiana in 2010. Currently in the Ph.D. program in the Physics department at the University of Toledo. His research focuses on thin film photovoltaic devices, device fabrication and characterization.

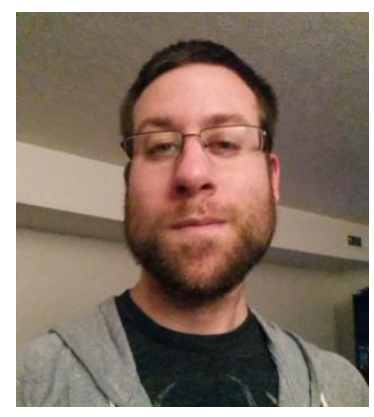

Xinxuan Tan received her undergraduate degree at Nanjing University of Information Science and Technology in 2009. She is currently a Ph.D. student in Dr. Robert W. Collins' group at University of Toledo. Her research focuses on spectroscopic ellipsometry analysis of thin films, including early stage nucleation, structure evolution, and temperature and stress effects on thin film.

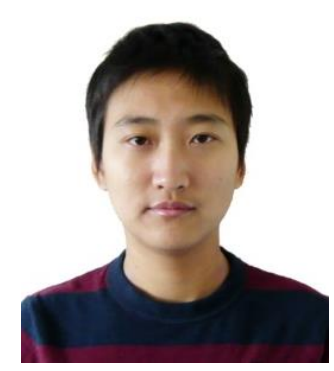

Mengjin Yang received his Ph.D in Materials Science from University of Pittsburgh. He is now a postdoc researcher at National Renewable Energy Laboratory. His research focuses on the development and characterization of hybrid solar cells and other optoelectronics. 


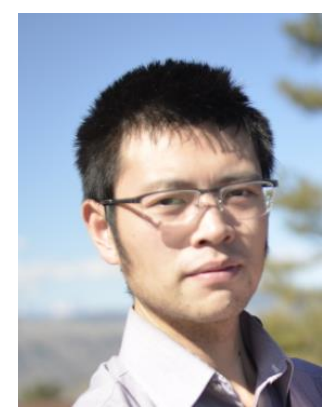

Robert Collins holds positions of Distinguished University Professor and NEG Endowed Chair of Silicate and Materials Science in the Department of Physics and Astronomy at the University of Toledo (UT), Toledo OH, USA. He received M.S. and Ph.D. degrees in Applied Physics from Harvard University in 1979 and 1982, respectively. He is a member of the Wright Center for Photovoltaics Innovation and Commercialization at UT and is a Fellow of the American Physical Society. He has been undertaking research and development activities in thin film photovoltaics since 1976, and instrumentation development in spectroscopic ellipsometry since 1982.

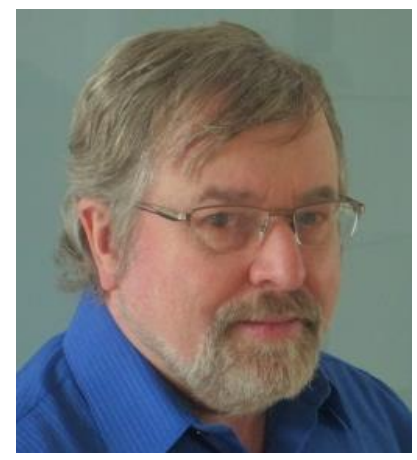

Hongmei Zhang is a full professor in School of Materials Science \& Engineering at Nanjing University of Posts and Telecommunications, China. She received her Ph.D. degree in Electrical Engineering from Jilin University in 2006. Her research focuses on device fabrication and characterization of organic optoelectronics (Organic solar cells, organic light-emitting diodes and perovskite solar cells) including optical design, various architectures and interface engineering.

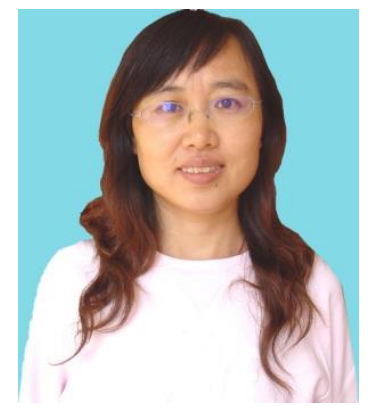


Kai Zhu is a senior scientist in the Chemistry and Nanoscience Science Center at the National Renewable Energy Laboratory (NREL). He received his PhD degree in physics from Syracuse University in 2003. His recent research is focused both basic and applied studies on perovskite solar cells, including material development, device fabrication/characterization, and basic understanding of charge carrier dynamics in these cells.

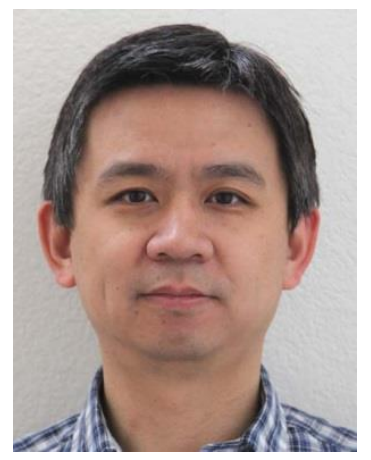

Yanfa Yan has been an Ohio Research Scholar Chair and Professor in the Department of Physics and Astronomy at The University of Toledo, since 2011. Previously, he was a Principal Scientist at the National Renewable Energy Laboratory. He earned his Ph. D. in Physics from Wuhan University in 1993. His expertise includes thin-film solar cell fabrication, defect physics of semiconductors, and nanoscale characterization of microstructures, interfaces, and defects in thin-film photovoltaic materials. He is a Fellow of the American Physical Society.

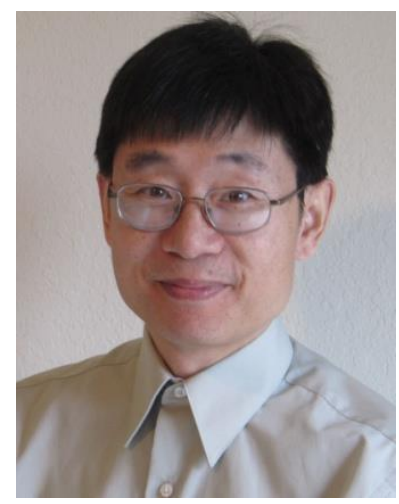




\section{Graphical abstract}

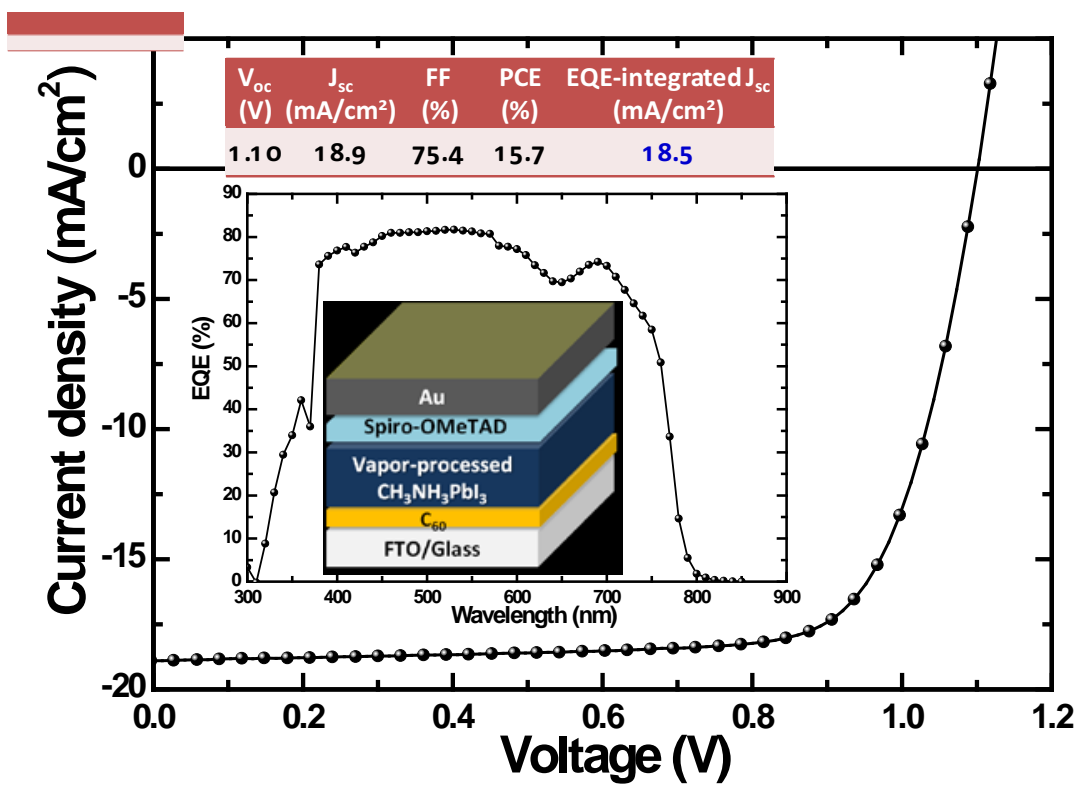

